\title{
Kuwait's Foreign Policy towards Regional Issues in the Middle East from 2003 to 2014
}

\author{
Mohamed Naser ${ }^{1}$ \\ ${ }^{1}$ Faculty of Economics and Political Science, Cairo University, Egypt
}

Received: August 30, 2017

doi:10.5539/ass.v13n11p95

\author{
Accepted: September 9, 2017 \\ Online Published: October 28, 2017 \\ URL: https://doi.org/10.5539/ass.v13n11p95
}

\begin{abstract}
Regionally, Kuwait has a unique foreign policy that is characterized by neutrality. This study investigates Kuwait's foreign policy towards regional issues in the Middle East in the period from 2003 to 2014. The study investigates the role of two tools of foreign policy: economics and mediation. The study investigates the role and implications of both economics and economic development assistance in activating foreign policy in Kuwait. It determines social, political, cultural and economic implications of economic development assistance in implementing and activating foreign policy in Kuwait. The study discusses some mechanisms of activating the economic foreign policy in Kuwait such as interdependence, soft power and national interests. It investigates mediation as one of foreign policy activation tools. The study suggests some ways for improving the efficiency of economic development assistance in implementing and activating foreign policy.
\end{abstract}

Keywords: Kuwait, foreign policy, Middle East, economic tool, economic development assistance, Mediation,

\section{Introduction}

Kuwait has great oil resources, amounting to 101.5 billion barrels in 2009 , representing $7.6 \%$ of the total oil reserve in the World.6 It is located in the Arabian Gulf region, which has strategic and economic importance for the world, simply because this region has $64 \%$ of the total world reserve of oil (Ghunaimi, \& Abdulmaqsoud, 2001), in addition to the events it witnessed from the late 1970s until the beginning of the 21st century. From its independence until the present day, Kuwait has used its diplomatic and economic tools to serve its external policy in order to occupy an important and effective position on the territorial and international level, in addition to the political and national objective, via granting loans and foreign aid to one hundred countries from 1961 until 2011 at a total value of KD 4.544 million (equivalent to $\$ 16$ billion) via the Kuwait Fund for Arab Economic Development (KFAED) (Kuwait fund, 2011). This is in addition to its confidential and sometimes undeclared contributions, which are beyond public control and are provided by Kuwait to some countries as a result of political and national considerations out of the 'General Reserve Fund' in the form of aid, such as foodstuffs or medication, which may not be easy to quantify. These financial contributions have been estimated at \$26.5 billion provided to Arab governments from 1963 to 1990 (Assiri, Abdul Reda, 1992). Since independence, Kuwait has endeavoured to activate the tools of its foreign policy and expand its diplomatic and economic activities towards a number of countries Following the collapse of Saddam Hussein's regime, several crucial changes came to characterize the foreign policy of Kuwait, one of which is that economic diplomacy became much more prominent, being designed to maximize benefits and increase the margin of political maneuver, and to construct economic alliances with the countries and blocks that have impacts on the world economy. Therefore, this study purposes to:

a) Investigate and analyze the role of Kuwait towards the Middle East region. Does Kuwait play a parallel role to some regional countries such as Saudi Arabia, Egypt and Iran in addition to Turkey?

b) Determine the limits of the role played by Kuwait compared to other countries in the Middle East? In what direction is this role played?

c) to identify the sources of the role and to explain its components, capabilities and possibilities of development and strengthening especially in the presence of a superpower that governs the world politics in the Middle East which is the United States of America.

d) to identify to what extent Kuwait's role is compatible with other countries. 


\subsection{The Study problem}

Given the role of both, economic development assistance and mediation in activating foreign policy in Kuwait, the problem of the study concern worries about the nature and limits of the role played by a small country such as Kuwait in the geographical region to which it belongs (the Middle East), and whether this qualifies it to play a certain role, and what is the form of this role and its tools and restrictions. Therefore, the research problem concerns with the interaction between three variables: the potential of the state, its role and the nature of the region to which it belongs. Accordingly, the study tries to answer to the main question: What is the regional role of Kuwait in the Middle East? Then, there are the following subsidiary questions of the main question, which are:

\section{1- What is Kuwait's vision of Middle East issues?}

2- What are the determinants of the Kuwait's role towards the Middle East?

3- What are the Kuwait's tools to deal with Middle East issues? Do they economic, military or diplomatic tools?

4- Has the Kuwaiti role been characterized by individual action by Kuwaiti state institutions or collective action through organizations belonging to Kuwait such as the Gulf Cooperation Council or the League of Arab States?

5 - What is the influence of foreign powers on the Kuwait's role?

6- What are the limits of the Kuwait's role or the restrictions on it?

\subsection{The significance of study}

The importance of the study stems from several theoretical and practical considerations as follows:

1- Theoretical consideration of studying the interaction of internal and external factors and their impacts on foreign policy determinations by analyzing the response of Kuwait to the changes taking place at several internal, regional and international levels, which characterized the period of the study.

2- The importance of studying the foreign policy of Kuwait towards the issues of the region. Kuwait's political and economic capabilities and its petroleum resources, especially in light of its strong relations with the major powers in the world, makes it capable of playing influential roles in the Middle East What highlights the importance of the study is witnessed by Kuwait during the period of study, especially in its economic dimensions, accompanied by an increase in the presence of the Kuwaiti role and its activities in many central issues in the region, whether in relation to the Iraqi issue or the Arab Spring revolutions and reform issues in the region with their different dimensions.

\subsection{The limits of study}

The place of the study is the Middle East. Choosing this region is due to the positive and negative developments, as well as transformations at the regional level that occurred in this region. The study tries to demonstrate the role of the smaller countries in this region that have active issues and development mobility during the study period. Thus, selecting the study of the role of Kuwait towards the Middle East region was due to theoretical and practical considerations. This role is represented in the importance of studying its dimensions and knowing the points of the weakness and strength of Kuwait's role in the region in order to create an integrated vision on how to deal with this role and its consequences and implications.

\section{Method}

To achieve the purpose of the study, the researcher followed historical and descriptive analytical methodology for description and analysis of a scientific phenomenon of Kuwait's foreign policy towards regional issues in the Middle East and determines the role of two basic tools for activating foreign policy in Kuwait; economy, and Mediation.

\section{Results}

\subsection{Economics as an Instrument of foreign policy in Kuwait}

The Diplomats usually demonstrate their opinions drawing on the experience of some of their peers who shifted from the rules and outlooks of the academic life to diplomatic practice as a key tool for implementing the foreign policy, those who discovered that the insights they have developed and formulated may not be fully consistent with the realities and assumptions of practical politics. From this point of view, economics as a diplomatic instrument provides an in-depth insight into the behavior of political players in a global system of world politics. However, the economic instrument from a partial perspective is a way or a tool not a global process. All international players have goals or objectives to which they direct their foreign policy. To achieve these goals, it 
is clear that the players need means often called tools in order to reach their destinations. Thus, economics provide an instrument used by international political players to implement their foreign policies either as a stand-alone tool or as a mean to notify other parties of other tools or threats, the economic tool as an instrument of foreign policy changes over time, especially in the contemporary world order( John Baylis \&Steve Smith, 2004). Foreign policy is the approach adopted by a country in its relation to other members of the international community. Some others identify it as Part of the international activity moving towards abroad and addressing issues that arise beyond the borders. It is true that the State try to respond to the behavior of other international parties through its foreign policy (Louis J. Genes 1989). By considering it as one of the political processes that achieve countries' relations and interests, the economic tool becomes inextricably linked to foreign policy and an essential part of it. The economic tool is considered both a preparation and implementation instrument of foreign policy through several peaceful and violent means. In order to achieve their interests, countries resort to these means, where the economic instrument is the basic mean of war or peace. This instrument never stops during peace or war (Allan I. Mendelowitz 1992).

\subsubsection{The Role of economic tool in implementing and activating the foreign policy:}

The concept of foreign policy varies according to the researcher's vision. Some researchers consider foreign policy as all the political behaviors aimed at and resulting from the interaction related to foreign policy decision-making of the country while the external behavior of a country is an event or a concrete act carried out by the State as a deliberate and intentional expression of its orientations in the external environment. Some other researchers identify it as a work schedule for external action, it specifically includes the objectives that the country seeks to achieve, the interests it is keen to secure and maintain, and the means and procedures it deems appropriate in accordance with its principles and beliefs (Mohamed Salem 2006). Foreign policy is one of the most important activities of the country through which it works to implement its objectives in the international community. The country is qualified to practice foreign policy because of its sovereignty and material and military capabilities (Jawad Hindawi 2005). The foreign policy of a country determines its behavior towards other countries, it is a program aimed at achieving the best possible conditions for the country by peaceful means that do not reach the limit of war (Muhammad Munther 2002). Foreign policy is directed to the external activity or to the external movement of the country. It is obvious that not every external activity necessarily involves a foreign policy unless such activities are linked to the achievement of country objectives. Foreign policy includes not only activities, but also programs, roles, objectives and policies (Ahmed Al-Naimi 2001). Talking about the field of international relations, the economic tool is used as a mean of international policy to deal with the family, the international community or with the international system as a whole or to deal with certain geographic regions. The field of external relations includes two distinct but closely related elements they are foreign policy and foreign relations management. In this case, perhaps one of the most prominent models at the American and European level is Henry Singer, whose historians recorded a disparity between what he preached about international power relations, and his diplomatic roles and initiatives. And on the Arab level, we can find the idea of Dr. "Ghali" when he moved from academic work and life to test these insights in political practice and to interpret the field of economic tool as a diplomatic instrument in the implementation of foreign policy (Boutros Ghali 1974 \& Henry Kissinger1995. The practice of foreign policy is not limited to the countries, but international organizations such as the United Nations and regional organizations such as the Arab League and even banks and trusteeships, and multinational corporations with their own personality have their own foreign policy that may be compatible with or different from their respective countries (R. A. Bauer et al 2000). In this context, some theorists tend to adopt the fundamental principle that Foreign policy and the economic tool are not synonymous. Foreign policy is the legislative aspect of the management of international relations and the economic tool is one of its executive aspects, which requires free acting experts. Foreign policy is one of the highest authorities of the state. Foreign policy is one of the responsibilities of the highest authorities of the country including the legislative authority, and the economic tool is the implementation of the policy rather than its preparation. This implementation does not require the attention of the public, as does the state budget. The public is interested in approving it rather than implementing it. The task of the economic instrument is not to defend a purely moral principle or to reward the forces of separation, but its task is to provide country relations that are sometimes harmonious and at other times contradictory, also the economic tool requires careful knowledge of the origins of conflict and making national proposals acceptable without sacrificing goals Of foreign policy (Mohamed Muhanna, 2006). These objectives must be put in a certain position coupled with a desire to achieve it by allocating the necessary amount of effort and possibilities that will be required to develop this situation from the purely theoretical stage to the stage of real existence. Although countries seek to achieve many goals, all these goals usually meet in one goal which is achieving the country's power and influence at the highest level through the implementation of the objectives and priorities of Foreign policy. This happens through 
the protection of operational means and tools, which are considered effective when they are compatible with the nature and strength of the country, which is the real school of international relations (Hadi Qubaisi, 2008). Hence, the impact of the economic instrument on foreign policy and their impact on international relations depends on several factors, most notably the degree of power of the country and the nature of the objectives it seeks to achieve. These factors determine the country's trends and the nature of its actions according to foreign policy variables. It should be noted in the context of the relationship between foreign policy and the economic instrument It should be noted that, in the context of the relationship between foreign policy and the economic instrument, there are two main stages included in the foreign policy process of countries: the stage of foreign policy-making and the stage of foreign policy implementation/ practice. Creation of foreign policy is the task of the government and is supervised by the highest authorities in the country. Foreign policy is so important for achieving country's interests. After decisions are made, they are handed over to the ministries of foreign affairs for implementation. In this case, the economic tool is one of the tools through which the decisions are implemented and foreign policy objectives and priorities are achieved (Maurice East, 1981). Diplomatic and Foreign Service personnel are trained in a network of embassies outside the borders of the country, which in turn constitute the diplomatic machinery of the government. If we identify the basic tasks that this machinery performs, we will immediately notice that they are not only related to foreign policy implementation but to its making tool (Selim , 1989). In this case it can be noted that the economic tool (one of the elements of government activity) is not only a political tool, but also a policy-making and implementation process as a whole as There are some of the major tasks that the economic tool performs as a diplomatic instrument for identifying, implementing and achieving foreign policy objectives (Alexander Gkeorge, 1980). These major tasks are: (information gathering, advice on politics, representation, negotiation, consular services. through these tasks we can say that the first two tasks are central to the creation of the foreign policy (Omar E. Joseph 1988). Information and data are the primary materials of foreign policy. Part of the work of diplomats abroad is to gather information and send it in reports to the political leadership in their countries. Information related to foreign policy making and implementation can be compiled from official and informal sources (John Baylis\& Steve Smith 2004). This happens when the diplomatic economic instrument is of a governmental nature.

On one hand, informal sources can be referred to as sources of economic tools for the implementation of foreign policy objectives, such as personal contacts with the political elite and the other diplomatic corps, diplomatic representatives of other countries resident on the site. On the other hand, the economic instrument provides an important tool for the implementation of foreign policies through representation, negotiation and consular services and providing assistance. The official bodies are not only representative of the government abroad but also represent the broader interests of the state, these interests that go beyond the narrow political sphere and which try to maintain a good relationship with host countries, which certainly requires the establishment of a network of relations with non-governmental representatives. This happens through following-up the relevant events that the host countries' national interests need to be encouraged and in which the informal bodies are active (John Baylis\& Steve Smith 2004). It can be said that both the economic tool and the foreign policy are complementary variables through the use of the economic tool to adapt the various formal and informal means within the foreign policy directions of countries and to provide the human and financial resources to achieve their objectives and priorities. In this sense, the economic tool remains one of the main tools in foreign policy implementation through its basic appearance, which is the provision of support and multi-aid and the implementation of objectives and priorities. the economic tool is not only gaining importance and is considered one of the most important tools of foreign policy, it also became an instrument in the direction of international affairs and has become a multi-functional, diversified and specialized profession aimed at serving the interests of all persons of the international community (Selim 2005). With the development of international relations and the expansion of the role of the country, many foreign policy forms and tools have been introduced by non-governmental representatives of official and informal bodies, which determine the nature of all forms of diplomatic exchange between countries and strengthen the relations of friendship and cooperation between the country and the people Which serves their mutual interests and the interests of international peace and security (Stephen Walker 1981). As a result of the growing role of these representatives, many theories have emerged. And the approaches discussed in defining the nature of the role in the field of international relations and the implementation of foreign policy (Selim 1989).

3.1.2 The effect of economic tool in implementing and activating the foreign policy:

In the light of the current changes, the international relations are based on the international agreements which are concerned with the organization and management of international affairs according to the standards of coexistence and dialogue among countries. The conduct of international relations is initiated through the 
activities of many bodies chosen by the country as a free country with the right to establish institutions and authorities which represent the people and the nation in the international life (Davidson \& Montville 1982). This right is determined on the basis of the needs of its Constitution. This constitution reflects the activities of the Government in a formal framework that forms the nature of the diplomatic practice and represents the image of countries in the international relations (Selim 2005). Economic aid diplomacy is a vital factor and one of the most important foreign policy tools used by the country. International finance literature refers to conflicting roles of international economic assistance. While some global experiences point to the positive impact of international aid on the country and the government by bridging the deficit gap in the country's economy, there are some other experiences pointing to the conditionality of this funding. The following are the most important conditions for providing economic assistance and its effects:

3.1.2.1 The conditionality of economic development assistance and its dimensions in implementing and activating foreign policy:

Conditionality and aid are inseparable, as there is no unconditional assistance, and political conditionality can be classified into several levels

- The highest level is the Interference with the country system, and the imposition of demands and policies such as democratic reforms, multi-party, and free elections

- Trying to change national policies and priorities.

- Trying to change specific policies in a particular sector, area or region such as taxes, prices, and legislation.

- Terms of financing (Kegley \& Mcgowan 1981): the donor country may put a condition such the expenditure of funding in a particular field or service without other services, for example, it may require spending it in the field of education or health without other services or fields.

- Administrative Terms (Thomath \& Skidmore 1997): the funding country may require that it manage the project from its inception until its implementation is completed or it may require that the costs of the project-based staff be paid by the recipient government.

Specifying the position of economic aid and donations varies according to the objectives of the donor countries and their terms and conditions as well. Unconditional aid and donations do not conflict with the legitimate direction. However, it must be understood that the conditions are not always political. But there are conditions that sometimes contradict with the economic philosophy of the country, such as stipulating that aid be directed to the support of private sector only. Some oppose these donations even if they are not accompanied by political, military or economic conditions because they are a form of humiliation that is incompatible with the state's prestige. However, as an exceptional matter, such aids and donations can be accepted but must not be relied on; they can be used as a temporary solution to the following problems facing the country. This kind of funding is full of negative effects including

-Its Irregularity makes it hard to rely on it as a permanent source of funding.

- The lack of clarity on the technical rules on which the aids and donations are granted, this means lack of justice in their distribution.

- The country is sometimes forced to use it in setting up certain projects that have been agreed upon in advance.

-It is not wise to expect a large volume of external grants as the Treasury will be embarrassed if the ambitious goal is not met. Therefore, there is no objection to the reservation in the grant and aid estimates, since receiving more than estimates will reduce the deficit and cause no financial confusion that could happen if the Treasury received less grants than budgeted.

3.1.2.2 Ways to improve the efficiency of economic development aids in implementing and activating foreign policy:

The efficiency of the use of economic development assistance and its ability to achieve economic and social progress in the beneficiary countries should depend on several points, including (Rashad Al-Assar et al, 2000).

- The existence of sound macroeconomic policies, programs of financial reform and effective criticism, economic openness and administrative reform in public administration, and the promotion of the private sector and social programs aimed at reducing poverty and addressing the gross inequalities in income distribution among citizens.

- Cooperation and coordination between recipient countries and international organizations. If the developing country is demanded for economic, social and structural reform, which will require the cooperation of both the 
private sector and civil society organizations with the public sector, donor countries, international organizations and bodies and development institutions should cooperate and coordinate with countries and work to solve their problems to raise the efficiency of the allocation of aid, whether these aids are financial or technical and the implementing programs and development plans (C. Lancaster, 2007).

- The appropriate timing to provide assistance to increase the capacity of developing countries that adopt economic and administrative reform and structural adjustment programs on the implementation of these programs efficiently by providing money required for the implementation of socio-economic reform and supporting social programs that work on reducing the negative effects of reform.

- Makes an appropriate combination of financial and technical assistance as development assistance plays a vital role not only in financing and supporting reform programs and in developing the service sector, but also in providing technical assistance and advice when developing plans, programs and development policy ((C. Lancaster, 2007).

3.1.2.3 Economic Implications of Economic Development Assistance in the Implementation and activation of Foreign Policy:

Development assistance provided over the last decades has been effective at different times and regions and hasn't been effective in other areas. A study issued by The World Bank indicates that assistance has helped to achieve many wonderful successes in many developing countries. In fact, this assistance has played a vital role In Indonesia and the two Koreas in the Seventies, Bolivia and Ghana in the 1980s, Uganda and Vietnam in the 1990s and Palestine in the twenty-first century. In all these countries, Economic development assistance contributed to accelerating economic growth and development by helping to develop public services, restructuring economic sectors, technology transfer, establishing infrastructure and achieving The green revolution, and the provision of financial resources which constituted the start of a self-financing dynamic that contributed to the creation of a favorable and attractive investment environment in the countries (Kegley \& Mcgowan 1981). Despite the successes achieved by some countries through the development assistance, this assistance has not played a positive role in the development of the economy in many other developing countries such as the Congo and Tanzania. This is because of the spread of administrative corruption and lack of transparency in government administration and the absence of effective macro- economic policies As the positive impacts of economic assistance on growth is achieved only in the case of countries that adopt sound fiscal and monetary policies that are mainly reflected in three main variables Budget deficit, inflation, and economic openness (Kegley \& Mcgowan 1981).

3.1.2.4 The social impacts of economic development assistance in the implementation and activation of foreign policy:

Development assistance provided by donor countries has contributed to raising human development outcomes in many developing countries, particularly in the areas of health, education, and strengthening social security, which have been reflected in reducing the illiteracy rates among the population, eradicating infectious diseases and reducing child mortality, and reducing extreme poverty.

There are many examples of the role of such assistance in providing human development in developing countries, such as efforts to combat HIV / AIDS and other public health problems (.Brecher \& Hatta 2001). Despite this positive evidence of the social impacts of aid, other scenes illustrate the negative impacts of aid and assistance programs, especially from some organizations and development agencies which require some conditions to provide assistance to developing countries, foremost of which is the lifting of subsidies on basic commodities, which causes the most severe losses to the poor social groups and contributes to the enrichment of certain groups that trade in these commodities (E. Beaulieu 2002).

3.1.2.5 The political implications of economic development assistance in implementing and activating foreign policy:

Although humanitarian and development concerns play a role in aid, their main motivations remain largely political or military. The pre-Cold War aid between the capitalist and socialist camps contributed to sustaining the contagion from the allied regimes of both camps and to building inclusive regimes. The assistance provided by these countries protected them against any external threats. The effects of this aid were providing opportunities for the establishment of military bases for donor countries and the provision of military facilities and logistical support in wars (A. Chong, \& M. Gradstein 2008). The desire of donor countries to establish circles of political influence and to enhance their military security is one of the factors affecting the nature and forms of such assistance. Some donor countries, particularly the United States, consider conditions are required 
to ensure the effective use of aid (R. Fleck, \& C. Kilby, 2001). It can be said that the most important negative political effects of the aid is the creation of dependent relations between donor and recipient countries, under which the recipient country becomes the captive of the influence of the donor country, and simulates its political orientations in international forums (Ibrahim Al-Esawi, 1991).

3.1.2.6 Cultural implications of economic development assistance in the implementation and activation of foreign policy:

Cultural impacts vary between negative and positive. Their effectiveness is not specific or even guaranteed, and their results are often non-developmental and have negative effects on social structure of the receiving community for the following reasons:

- Countries and bodies that provide or manage assistance are based on cultural assumptions that need to be re-examined. They are based on the assumption that Western culture is universal and valid for all human societies, and that local cultures are backward cultures lacking institutions. Consequently, the solutions offered were typical solutions based on the Western world, both in terms of its vocabulary and its application. This assumption or misunderstanding of non-Western cultures led to the failure of many assistance even in its partial form of specific projects carried out by foreigners.

- These cultural and social negative effects have accumulated for external foreign aid and have interacted with the value-added stock of the recipient communities. The result is complete loss of the cultural immunity of the society and the incidence of total cultural erosion. For example, the Arab culture carries a great appreciation for those who provide assistance or aid and gives them all the glory and respect. In the Arab culture, thanking God is out of thanking people, so, thanking favors and acknowledgement are of the good of Arab virtues (Ibrahim Al-Esawi, 1991). The main cultural impacts of economic aid and assistance can therefore be monitored as follows: (Ibrahim Al-Esawi, 1991)

- The flow of foreign financing in its various forms has distorted the pattern of production and consumption. This has led to a state of relaxation in the national saving due to the spread of consumer value in the society and reliance on external sources of aid.

- Scientific and cultural dependence on the developed state, the spread of negative values and lack of initiative.

- The creation of a class of beneficiaries and corrupt politicians who loot and exploit aid and turn it into personal benefits in the form of overpayments, missions and trips abroad at the expense of aid projects or in projects do not relate to the development of society.

- In the case that such aid is provided to civil society or non-governmental organizations, this would lead to the removal of the country sovereignty in the long run. Also, it would lead to the implementation of an agenda hostile to the country, albeit unconsciously by NGO officials, where assistance is usually provided for the implementation of projects, whether scientific, social or cultural, which may not be a priority of those organizations if left the role of external influence.

3.1.3 Mechanisms of activating the economic tool in foreign policy:

During the last decade of the twentieth century, a number of changes and terminology were common, such as interdependence, equal exchange and equal dependence, which reflect a number of changes in international relations in the last decade of the century, especially the period of the Cold War and the world of modernity. With a global trend within what is called the view of interdependence at the economic level, which calls for the need to liberalize world trade and this requires the launch of initiatives to strengthen the role of the private sector, businessmen and investors, and their role in the international economy and the opening up of markets in the context of international legislation that will make the global market a single open market without barriers (Katherine Barbier \& Gerald Schneider, 1991).

\subsubsection{Interdependence as a mechanism for activating the role of economic instrument in foreign policy:}

By considering the theory of interdependence as a mechanism for implementing the role of the economic instrument in activating foreign policy, the theory of interdependence gives great importance to the development and promotion of the concept of international economic cooperation as the actual entry point for achieving cooperation among nations and to create dialogue among peoples at the highest levels. In order for this international cooperation to prevail on strong pillars of equal exchange and interdependence, dialogue between developed countries and other developing countries should be strengthened through the integration of non-governmental representatives such as the private sector and businessmen in order to establish relations in 
line with all international variables (Jean- Marc F et al, 2000). All types of actors can influence political outcomes, but the claim that only the country has the power to influence international relations within the conventional perspective of international relations is an unacceptable analytical bias. Some eminent thinkers on the country recognize this point within a very narrow range, arguing that non-state elements and actors should only be taken into account when these elements affect inter-state and not otherwise (John Baylis, \& Steve Smith, 2004). The phenomenon of international interdependence is a characteristic of the modern political system. The phenomenon, despite its limited scope and limited movement, in certain historical stages, due to technical progress and qualitative development in transport and communications, has emerged in an intensive and unprecedented manner. These developments created a tendency for the units of the international system to satisfy the growing needs of their peoples by engaging in cooperative interactions to the trend that made their interdependence an upward one (Joseph C. Tai, 2003) \& (Marwa Mahmoud Fikri, 2004). It should be noted that interdependence is an ambiguous expression that is used in many different ways, like other political phrases such as nationalism and imperialism. At the analytical level, however, the word refers to a situation in which multiple people or events in different parts of a particular system affect each other (Biko Barik , 2013). simply the word means of 'common dependence:, and this position itself is neither good nor bad and there can be more or less than it (Joshua S, Goldstein, 1999) \& (Wadouda Badran, 1996). On the other hand, the interdependence is to increase the degree of exposure to economic shocks emanating from the outside world. If this is true of all members of the international economic system, this means that the level of economic performance in any other country depends not only on what happens within the country, but also on what happens In the other countries associated with it in trade or financial relations. Economic shocks in this context are not meant to be only economic changes with negative effects. Impacts from abroad may be positive, helping to increase growth rates, reduce inflation, and raise employment or otherwise (Saeed Al-Najjar, 1990). In general, dependence means "the situation in which influence is exercised by an external force." Mutual dependence simply means mutual or reciprocal dependence. In foreign policy, interdependence refers to a situation characterized by reciprocal influences between countries or between representatives from different countries. These effects are often the result of international transactions, such as flows of money, goods, people and messages across international borders. These transactions have increased dramatically since the Second World War. Each decade of war follows operations that double over the previous decade (Robert O, Keohane, Joseph S, Nye, 1989). By applying the mechanism of interdependence in the interpretation of Kuwaiti-regional international foreign policy, The Kuwaiti strategy in its regional context is primarily concerned with the economic aspect, although it has other non-economic dimensions. The presence of Kuwait in its regional environment is multifaceted. Besides the presence of the international community, Kuwait is heavily dependent on private and multinational investments and partnerships that invest heavily in its regional environment (Kenneth Katzman, 2012).

\subsubsection{Soft power as a mechanism to activate the role of economic tool in foreign policy:}

The military and economic forces are examples of solid power and can be used to persuade, "the carrot" or to threaten, "The stick". But there is an indirect way to practice foreign policy. A country can get the results it wants because other countries respond to its values, like its ideals, and aspire to reach its level of prosperity. This kind of power makes others want what they want, it's the Soft power (Joseph S. Nye \& Jr, 2002 ). It is accompanied by non-material resources such as culture, ideology and institutions. In contrast to the solid force that is usually associated with material means (Mohamed El Sayed Selim, 2005). The soft power is not necessary against the solid power. Soft power is based on setting the agenda in a way that shapes the preferences of others. The ability to demonstrate preferences is linked to the sources of intangible power, culture, creed, and gravitational institutions. It's a country's capacity to create a situation where other countries can develop their preferences or recognize their interests in a manner consistent with the preferences of that country. This type of power is derived from resources such as economy and cultural or ideological viability and from the rules and institutions of international systems (Joseph S. Nye, 2002). The criticism of soft power as a mechanism for implementing the role of the economic instrument in activating foreign policy is based on two elements: the first is the separation between solid power and soft power - many theorists reject this separation. The soft power, despite all its advantages, and its results, will remain useless if it is not based on a strong economic and military power, as evidenced by several countries like Japan, Germany and Canada, despite all the political, ideological, and cultural systems that are attractive, have a very relative impact on the outcomes of global policy (Micheal W. Doyle, 1997). The second element, giving priority to soft power in global hegemony, is an inaccurate and relative proposition. All that is promoted is the retreat of the military variable, but it remains the decisive factor in ensuring the hegemony of countries. The US military invasion of Iraq is a good example of this; The United States of America did not need international institutions, ideology or culture to impose its hegemony over oil sources in Iraq, but to a huge military arsenal (Muhammad al-Sa'id Idris, 2003). As Tai says, "what has been said 
does not suggest that military power no longer has a role to play in international politics today". On the one hand, the greater part of the world has not been transformed by the information flow revolution. Power in the globalizing information age is shifting to less stereotyped and less coercive things, especially among developed countries. But most of the world is not made up of post-industrial societies and this limits the transformation of power. Large parts of Africa and the Middle East are still trapped in pre-industrial agricultural societies, their institutions are weak and their rulers are domineering. Other countries, such as China, India and Brazil, are with similar economies to some parts of the West in the middle of the twentieth century. In such a diverse world, all sources of military and economic power remain possible, and are related to different degrees in different relations (Joseph C. Tai, 2003).

\subsubsection{The national interest as a mechanism for activating the role of the economic instrument in foreign policy}

The recognition of the national interest, according to the theory of interdependence, raises problems; because the orientation of foreign policy has a political aspect, from the logic of the simultaneous presence of groups with contradictory interests on a given issue (Naseef Yousef, 1998). The national interests go beyond the private interests, but, they are internal, "invisible", determined by the internal societal demands of the international community rather than external environmental factors. It can be concluded that they are not unitary but pluralistic considering the pluralism of civil society (Joanne Gowe, \& Edward B. Mansceld, 1993). Realists believe that the country's position in the international system has defined its national interests and its foreign policy. Liberals say that the definition of national interests depends to a large extent on the kind of internal society of that country. For example, a society that places economic prosperity and trade at the highest level of importance, or that society that looks at Wars against other democratic countries as illegal, such a society has defined its national interests in a way that is very different from the definition of a society living in a tyrannical country with the same status. If the institutions and channels of communication expect stable lasting peace, it is possible to get out of the prison dilemma (J, Peter Pham, 2008). With the development of international relations today, the economic instrument becomes the main access through which we can achieve the policy of peace and war and the protection of the interests of countries and individuals, through various, diverse and specialized functions aimed at serving the interests of all people of the international community. This is done by bodies and groups that carry out these activities, as they are necessary elements in any logical relationship between individual and country. Such activities aim at strengthening friendly and peaceful relations between countries and nations and work to restore the risk of war and its continued readiness (Harold Niekoson, 1997). Since the economic tool is an important process of communication and negotiation in the world politics, it is based on two basic perspectives: the macro analysis, the big picture, and the micro analysis of the small picture. The former tried to understand global politics and international relations and its constituent parts as a whole, Global and International Relations From the different perspective of those involved in global politics and international relations, it focuses more on understanding the behavior of foreign policy of countries, governments and those acting on behalf of those countries (John Baylis, \& Steve Smith, 2004). These practices arise within a set of tracks called Tracks Diplomacy. Whether these tracks were formal or informal, they aim at preserving international peace and promoting dialogue among nations and peoples, which is increasing its role through coordination among them, playing an observer role in the conduct of international relations, collecting information and investigating the causes of conflicts between nations.

All these tracks are in themselves a system with its tools, means and methods working to achieve the objectives of this system. Therefore, if all these paths with their capabilities and potentials met to promote dialogue and peace between peoples, they fall within the general framework called Multi-track diplomacy. This concept, which has been put into practice by some, means the activities of these tracks from Track One to Track five (John W. MckDonald,2008). The main objective pursued by the economic instrument is the establishment of direct relations between all peoples in the world. These peoples are the parties to diplomatic and international relations with a real interest in establishing a secure and interactive world and achieving the interests of the common and interrelated peoples in various fields. The objectives of the economic tool within its official framework differ from its objectives within the informal framework. The economic instrument at all levels aims at establishing direct relations between peoples in multiple, varied and different ways.

\subsection{Mediation as one of foreign policy tools in Kuwait:}

Mediation is an important factor for negotiations. When mediation is successful, it provides a means for the parties to live together despite the conflict between them. Mediation doesn't provide a deep interest and does not eliminate the causes of the conflict. The parties can determine their fighting or violate a cease-fire if left unchecked. This is the reason why some scholars and practitioners in this area recommended that the role of mediator be more interventionist after the settlement of the conflict than before. 
The mediation is optional, meaning that the state mediating the dispute is a volunteer and thus the conflicting countries are free to accept or reject the mediation, without being considered violator of the international law, although the refusal is an unfriendly act. Mediation is similar to good offices in that both are used either to prevent war or to end a war between two countries or to resolve differences and conflicts. In order to avoid the political pressure exerted by the mediator state on the opposing parties or its bias, there was a need to resort to an independent personality qualified to act as a mediator.

It can be said that mediation is the effort of an independent third party qualified to act as a mediator. Mediation can be an effort by an independent third party outside the main and secondary conflicting parties and neutral to assist the parties in reaching a resolution of the dispute. Here, It should be noted that the legitimacy of the mediator and the manner in which he intervenes to assist the parties of the conflict vary greatly according to different cultures and societies (Ziad Al-Smadi, 2010). The role of the mediator state is to mediate by its will without being forced to do so. In contrast, the conflicting countries have the freedom to accept or reject the mediation. Hence, we find that the State of Kuwait played the role of mediator in many times without asking any of the conflicting countries, thus we find that these countries accept the mediation of Kuwait.

\subsubsection{Kuwait as a mediator}

The systematic approach of Kuwait's financial capabilities gave the power, influence and credibility to play the role of mediator in regional conflicts in order to reduce tensions between the Arab world and the Middle East. This role in itself increases Kuwait's credibility as a "central" country in Arab politics. Kuwait's role is either as a respond to calls from abroad or as an initiative taken by Kuwait itself. This role can be described by "many are expecting Kuwait to have a mediating role in many problems and conflicts in the region." Kuwait knows that peace and cooperation among the nations and peoples of the world is not only one of the meanings of goodness inherent in its Arab Muslim people, but it also for Pragmatic urgency and obvious geopolitical reasons (Rashid Al-Rashed, 1984). The first Kuwaiti mediation test took place in the mid-1960s when a meeting between the parties was organized for both "Republicans and Royalists" in Yemen with the presence Egypt and Saudi Arabia, and although the outcome of the meeting was inconclusive, the Crown Prince and Prime Minister Sheikh Sabah Al-Salem visited Riyadh in June 1965 and held talks with King Faisal to find ways to solve Yemen's problem. In August 1966, meetings were held in Kuwait with representatives of Egypt, Saudi Arabia and Yemeni political parties. Kuwait offered a suggestion, which was approved by the parties concerned, but never implemented. The suggestion was to form a transitional government of both public and royal parties with a republican majority and the presence of Egyptian forces which withdrew later, and replaced by joint Arab forces (Abdul-Rida Asiri, 1993). In 1968, Kuwait intervened and created a climate conducive to solving the problem of Iran's claim to the Bahrain, and several meetings were held between the representatives of the governments of Tehran and Bahrain at the headquarters of Kuwait's representative in Geneva before the parties agreed to present the case to the United Nations where there were good mediation efforts. Kuwait unsuccessfully tried to mediate in the Shatt al-Arab problem between Iran and Iraq in 1969. The Kuwaiti prime minister said that the Emir was trying to exploit his efforts to resolve the dispute. Kuwaiti representatives visited both Baghdad and Tehran.

In the early 1970s, Kuwait tried to resolve the dispute between East and West Pakistan, and its Foreign Minister, Sabah Al-Ahmad, sent a delegation of good offices of the Organization of the Islamic Conference To Dhaka and Islamabad. The delegation finally managed to reduce the tension between Bangladesh and Pakistan through trying to normalizing relations between them (Abd al-Rida Asiri, 2000). Kuwait tried to mediate between northern Yemen and southern Yemen in September 1972, except for skirmishes on the common border. However, the efforts of Kuwait alone were not fruitful, but through its membership in a UN committee, it was able to visit the two countries in October 1972 and contribute to ending the dispute between the two parts of Yemen (Abdullah Y. Bishara, 2002). Kuwait participated in the unified Arab efforts to end the civil war between the Palestinians and the Jordanians in September 1970. Kuwait launched its efforts to shed Palestinian and Arab blood in the events of September 1970, and the leadership of the Palestinian revolution was protected. Kuwait's Minister of Interior and Defense Saad Al-Abdullah played an important role in the efforts of the Arab League Committee to find a compromise between the two warring parties. There is no doubt that Kuwait's efforts have increased its strength and reputation among Palestinians and Arabs, both internally and externally (Abdul Aziz Al-Duaij, 2010). The Omani-Yemeni crisis is one of the most successful attempts by Kuwait with the GCC countries to resolve the regional crises. After many meetings, the Foreign Ministers of Aden and Muscat agreed (at a meeting in October 1984 in Kuwait attended by the Foreign Ministers of Kuwait and the United Arab Emirates) in principle not to interfere in the internal affairs of both countries, respect the sovereignty and territorial integrity of both parties, end the propaganda and media war and establish diplomatic relations between them. The former Undersecretary of the Ministry of Foreign Affairs, Rashed Al-Rashed, described the new 
agreement as "building a great relationship of trust and limiting the intervention of the major Powers (Salman Majid Al-Shahain, 1984). Kuwait had an active role in the Arab political disputes and crises. This role emerged during the Lebanese civil war since its outbreak in 13/4/ 1975 to the end of the year 1990. Kuwait called for an emergency meeting of Arab foreign ministers to discuss the situation in Lebanon. In the mid-1980s, Shaikh Sabah Al-Ahmad called on the Lebanese leadership to attend a conference in Kuwait to discuss ending the Lebanese civil war. The various Lebanese political and religious leaders met in Tunis and Kuwait in early 1989 to work towards a satisfactory solution to the thorny Lebanese problem. As a promotion to the Islamic role and interests of Kuwait, it tried to mediate between Turkey and Bulgaria to solve the problem of the Turkish Muslim minority in Bulgaria. Kuwait held meetings between the Ministers of Foreign Affairs of the two countries in Kuwait at the end of 1989. From 1946 to 1984, the Government of Bulgaria carried out arbitrary measures against the Turkish Muslim minority in its territory, especially with regard to their Islamic culture and rituals. At the end of 1984, the Bulgarian forces launched a military campaign in areas inhabited by a Muslim majority. Turkey began to move regionally and internationally to force Bulgaria to stop and several countries, including the Gulf States (Kuwait, for example) responded. Bulgaria In May 1986, Bulgaria called for a satisfactory settlement. The follow-up committee was formed at the summit of the Islamic Conference held in Kuwait in 1987 (Ibraheem Al-Qallaf \& Methaq Glood, 2006). Kuwait's success in the mediation role, according to Foreign Ministry Undersecretary Suleiman Majid Al-Shaheen, stems from "the credibility of Kuwait's behavior, the tendencies of its non-negotiable foreign policy, the fixed model of its policies and its financial strength. Kuwait's financial capabilities, including loans, aid or investments through public institutions or private channels, have played a supportive and stimulating role for foreign policy and influence and make Kuwait's role in mediation more bearable. Sheikh Sabah al-Ahmad's personality is a key and organic part of Kuwait's foreign policy success. Foreign relations are subject to the mood, taste and personal desires of the official and may lead to complications with other countries and political confusion or lead to bureaucratic stalemate. The centrality and secrecy of the decisions of the foreign policy may make them liable to error; the collective decisions are more objective and rational (Assiri \& Abdul-Reda, 1993). Kuwait has played a major role in the unification and coherence of Arab countries and resolving differences among them. Kuwait and Saudi Arabia played a big role in the establishment of the United Arab Emirates, represented by Prime Minister Shaikh Sabah Al-Ahmad, as a leading role in the establishment of a federation comprising the nine emirates (United Arab Emirates, Bahrain and Qatar). Despite the efforts exerted by Kuwait, however, the differences arose because of the capital of the Union, the distribution of ministries and other things, in addition to Bahrain's declaration of independence in 1971 followed by Qatar in1972. The Union became out of seven emirates instead of nine, which included the United Arab Emirates (Abdullah Yusef Al-Ghunaim, 2004). Kuwait had no desire to join the Union because of its location and geographical distance. Between 22 and 27 June 1968, Foreign Minister Shaikh Sabah Al-Ahmad Al-Sabah visited Qatar, Bahrain, Abu Dhabi and Dubai. His Highness also met with the five governors of the Northern Emirates and suggested establishing a federal court and a federal council to assist the Supreme Council and thus elect the first president of the Union. The Foreign Minister also stressed the need to agree on a limited basis. As a result of the Kuwaiti suggestions, The Supreme Council was held in Abu Dhabi 6- 7 July 1968. This meeting was able to establish a temporary union council consisting of nine members representing each emirate. Sheikh Khalifa bin Hamad Al Thani was also appointed as Chairman of the Federal Regional Council (Muhammad Al-Roumi, 2010). The distinguished role and sincere efforts exerted by the Kuwait in its usual wisdom in cooperation with the Arab countries, which have received great appreciation and encourage among the conflicting parties and whose result is the achievement of the settlement of differences.

\section{Conclusion}

It can be said that Kuwait's foreign policy has politically matured. It is based on neutrality. The cardinal principle on which the foreign policy of Kuwait is based had been enunciated by the late Amir of the State of Kuwait Sheikh Jaber Al-Ahmad Al-Jaber Al-Sabah, when he declared that, "Kuwait lives under the protection of Islam as its religion, Arabism as its homeland, cooperation as its strategic path, tolerance as its motto, fraternity as its guidance, constitution as its modus operandi, justice as its rule, progress as its responsibility and peace as its goal". The objective of Kuwait's pursuit of diplomacy is based on a pragmatic and balanced approach and is conducted in accordance with the government's philosophy and the interest of the State. Kuwait adheres to a policy, which is characterized by clarity, straightforward and quiet diplomacy. It strives to strengthen constructive cooperation with all countries on the basis of mutual respect and non-intervention in the internal affairs of other States in accordance with the principles of fairness and justice. Further, Kuwait doubled its contribution to various international Organizations and has been playing a leading role in support of the humanitarian work globally. 


\section{References}

Abdel-Fattah S. et al. Foreign Aid and Development in the Arab World: Vision from an Arab and Islamic Perspective.

Abdulmaqsoud, Z. G. (2001). Al-Kuwayt wa taḥadiyāt al-karn il-ḥādi wal 'ishrīn: Ru'yah Strātīīìyah was-tishrāfìyah 'Kuwait and the Challenges of the Twenty First Century. Strategic and Futuristic Vision', 1 st edition, Center for Research and Studies on Kuwait, Kuwait, P. 24.

Al-Assar, R., et al. (2000). International Finance, Amman / Jordan, Dar Al-Mesira for Publishing. Distribution and Printing, 81- 89.

Al-Duaij, A. A. (2010). Foreign Policy of Kuwait through the Ministry of Foreign Affairs (P. 27). Ministry of Foreign Affairs of Kuwait, Department of Research and Information, Kuwait.

Alessina D. D. (2000). Who gives foreign aid to whom and why? Journal of Economic Growth, 5, 33-41.

Al-Ghunaim A. (2004). His Highness Sheikh Sabah Al-Ahmad, "Determination and building", Kuwait Research and Studies Center, Kuwait, p. 8.

Al-Qallaf I, G. (2006). Gulf Relations of Turkey, Center for Regional Studies, Regional Studies, p.15.

Al-Majran, M, A. (2010). Diplomatic Role in the Foreign Policy of Kuwait, Ministry of Foreign Affairs of Kuwait, Kuwaiti Research Department, Kuwait, p.7.

Al-Naimi, A. (2001). Foreign Policy, Baghdad, Baghdad University Press, Ministry of Higher Education and Global Research, pp. 14-19.

Al-Najjar, S. (1990). interdependence and labor economy with reference to the Arab reality, in: Saadi Taher Kanaan, Ibrahim Saad (Eds.), Interdependence, economic integration, and Arab reality: a comparative study of the theory, study, and study of the unit Arab Countries, pp. 14- 17.

Al-Rashed, R. (1984). Mediation in Kuwait's Foreign Policy, Lecture in a Training Program, Department of Political Science, Kuwait University, Kuwait, p. 5.

Al-Smadi, Z. (2010). Conflict Resolution (Revised Version of the Jordanian Perspective), International Peace Studies Program, United Nations University of Peace, p. 55.

al-Sawy, I. (1991). The great betrayal in the Shatt al-Arab of the articles Shahadou pen, the crisis of Kuwait in the eyes of the book of Egypt Part II, the media center of Kuwait, Cairo.

Al-Shahain, S. (1984). Negotiation in the Foreign Policy of Kuwait, Al-Watan Magazine, Kuwait, /10/31 P. 4.

Asiri, A. (1993). Kuwait in Contemporary International Politics: Achievements, Failures and Challenges, Al-Qabas Commercial Printing Press, Kuwait, p. 128.

Asiri, A. (2000). The Political System in Kuwait: Principles and Practices, edition 5, Kuwait University, Kuwait, p. 114.

Assiri, A. (2002). 'Kuwait in the Contemporary International Policy: Achievements, Failures and Challenges', 2nd edition, Kuwait University, Kuwait, 1992. p.116. Abdullah Y. Bishara, The Secretary-General's Daiary, Diplomatic Center for Strategic Studies, Kuwait, p.235.

Badran, W. (1996). The study of international relations in Western literature and the project of international relations in Islam, Nadia Mahmoud Mustafa (ed.), Project of International Relations in Islam, Part I, Cairo, Higher Institute of Islamic Thought PP. 64- 67.

Barbier, K. S. (2012). Globalization and Peace: Assessing New Direction in the Study of Trade and Conflict. Journal of Peace Research, 36, 391-396.

Beaulieu, E. (2002). Factor or Industry Cleavages in Trade Policy? An Empirical Analysis of the Stopler-Samuelson Theorem. Economics and Politics, 14, 104-111.

Barik, B. (2013). A New Identity Policy Political Principles for Interdependent World, Cairo, The National Center for Translation, pp. 71-64.

Bauer, R. P. D. (1997). American Business and Public Policy: The Politics of Foreign Trade, Chicago, Aldine-Atherton, IL., pp. 41-46.

Baylis, J. S. (2004). The Globalization of World Politics, An Introduction to International Relations, New York, Oxford University of Press, Second Edition, pp. 321-326 
Bhagwati, J. B. H. (2001). The Generalized Theory of Transfers and Welfare: Bilateral Transfers in A Multilateral World. American Economic Review, 73, 62-66

Chong, A. G. (2008). what determines foreign aid? The Donors' Perspective. Journal of Development Economics, $87,7-11$.

Doyle, M. (1997). Ways of War and Peace: Realism, Liberalism, and Sociallism (pp. 54-58). New York: W. W. Norton.

Davidson, W. V. M. (1981-1982). Foreign Policy According to Freud. Foreign Policy, 54, 541-551.

East, M. (1981). The Organizational Impact of Interference on Foreign Policy Making: The case of Norway. In C. Kegley \& P. Mcgowan (Eds), The Political economy of Foreign Policy (pp. 138-141). Sage: Beverly Hills.

Fikri, M. (2004). The Impact of Global Transformations on the National State during the 1990s: A Case Study, Unpublished Master Thesis, University of Cairo, Faculty of Economics and Political Science, pp. 91-93.

Fleck, R. K. (2001) Foreign aid and Domestic Politics: Voting in Congress and the Allocation of USAID Contracts across congressional districts. Southern Economic Journal, 67, 602-605.

Gowe, J. M. (1993). Power Politics and International Trade. American Political Science Review, 87, 414-418.

George, A. (1980). Presidential Decision making in Foreign Policy: The Effective Use of Information and Advice, Boulder, West view Press, 169-173.

Genes, L. (1989). Interpretation of Foreign Policy, Translated by: Hamad bin Ahmed Mufti and Muhammad Al-Sayyid Salim, Riyadh, King Saud University, pp. 184-181.

Ghali, B. (1974). Politics and Development in Africa, Cairo, the Anglo-Egyptian Library, pp. 71-85.

Goldstein, J. (1999). International Relation N. Y: Longman, pp. 100-103.

Hindawi, J. (2005). The Foreign Policy of the American Administration: Research in Law and Politics, Beirut, Dar Al-Rafidain for Printing, Publishing and Distribution.

Hussain S. (1992). Issue No.108 for the International Politics Magazine, under the title: Dr. Boutros B. -Ghali as a political analyst, specialized journalist and international diplomat, international policy, Cairo, Al-Ahram Foundation, pp. 35- 108.

Idris M. (2003). The Defeat of Iraq; Political and Economic Implications, in Ahmed El-Naggar et al., The defeat of Iraq, Political and Economic Impacts, Cairo, Al-Ahram Center for Political and Strategic Studies.

Jean- Marc F, B, D, M, \& R. (Eds) (2000). Power and the Purse: Economic Statecraft, Interdependence and National Security, London Frank Cass, pp.41-46.

Joseph O. (1988). The role of the Foreign Ministry in the decision-making of the Egyptian foreign policy in the period 1952-1952, a published master thesis, Faculty of Economics and Political Science, Cairo University, p. 154.

Katzman K. kuwait: Security, Reform And U.S, Policy, Congressional Research Service, CRS Report for Congress Prepared for Members and Committees of Congress, October 9, P. 7-14.

Kegley, C. M. (1981). (Eds). The Political Economy of Foreign Policy, Sage: Beverly Hills, pp.42 46.

Kissinger, H. (1995). Diplomacy from the Seventeenth Century to the Beginning of the Cold War, translated by Malik Fadhil al-Budair, Amman / Jordan, Dar al-Ahlia Publishing and Distribution, pp. 60-68.

Kuwait Fund for Arab Economic Development, Forty Nine Annual Report 2010 /2011, Kuwait, 2011.p.13.

Lancaster, C. (2007). Foreign Aid: Diplomacy, Development, Domestic Politics, University of Chicago Press, Chicago, IL , pp. 54-62.

Lairson, T. S. (1997). International Political Economy: The Struggle for Power and Wealth, Florida: Harcourt Brace \& Company, pp. 23-28.

MckDonald, J. (2008). Multi- Track Diplomacy: Conflict Resolution for the New Century University of British Columbia Faculty of Law: http://www.politics.ubc.ca/index.php?id=9976,12/09/2008.

Mendelowitz, A. (1992). Economic Sanctions Effectiveness as Tools of Foreign Policy, Report to the Chairman, Committee on Foreign Relations, U.S. Senate, Washington, D.C., United States General Accounting Office, pp.12-16.

Muhanna, M. (2006). international relations from globalization to Americanization, the modern university office, 
pp. 153- 156.

Munther, M. (2002). Principles in International Relations: From Theory to Globalization, Beirut, the Glory of the University Foundation for Studies and Publication, pp. 144-145.

Niekoson, H. (1997). Diplomacy, translation: Mohamed Mokhtar Zaqzouki, Cairo, The Anglo-Egyptian Library, pp. 41-45.

Pham J. (2008). What is in the National Interest? Hans Morgenthau,s Realist Vision and American Foreign Policy, American Foreign Policy Interests, No.30, pp. 259-262.

Qubaisi H. (2008). American Foreign Policy between Two Schools: The New Conservative and Realism, Beirut, Arab Science House, p.33- 51, Publisher.

Salim M. (1989). Planning of Egyptian Foreign Policy in a Changing World, International Politics, Cairo, Al-Ahram, October 89, pp. 79-82

Salim M. (2006). Analysis of Foreign Policy, Cairo, Ameen House for Printing, Publishing and Distribution, 1998, 2 pp., 84-80, Ali Wajih Mahjoub: Trends in American Foreign Policy in the 21st Century and the New International system, unpublished Ph.D. dissertation, Faculty of Political Science, Al-Nahran University, Baghdad, , pp. 19-1. (2005), Evolution of the theoretical Framework of International Politics, International Policy, Cairo, Al-Ahram Foundation, No. 161. PP. 47- 48.

Mohamed Said Salem (2006). Analysis of Foreign Policy, Cairo, Ameen House for Printing, Publishing and Distribution, 1998, 2 pp., 84-80, Ali Wajih Mahjoub: Trends in American Foreign Policy in the 21st Century and the New International system, unpublished Ph.D. dissertation, Faculty of Political Science, Al-Nahran University, Baghdad, , pp. 19-1.

Robert, O, K, J, S, N. (1989). Power and Interdependence: World Politics in Transition (2nd ed.). Boston. Little Brown, , pp. 9-16.

Tai, J. (2003). The Paradoxes of American Power: Why the World's Only Great Power Cannot Go Alone, translated by Mohammed Taufeek Al-Bajirmi, Riyadh, Al-Obeikan Library, p 38- 39.

Tai, J. (2003). The Paradoxes of American Power translated by Mohammed Taufeek Al-Bajirmi, Riyadh, Al-Obeikan Library, pp 78-79.

Tai, J. (2002). Jr., Limits of American power. Political Science Quarterly, 117(4), 520-552.

Walker, S. (1981). The Correspondence between Foreign Policy Rhetoric and Behavior: Insights from Role Theory and Exchange Theory. Behavioral Science, 26, 272- 277.

Yousef, N. (1998). Theory in International Relations (pp. 93-98). Cairo, Dar al-Kitab al-Arabi.

\section{Copyrights}

Copyright for this article is retained by the author(s), with first publication rights granted to the journal.

This is an open-access article distributed under the terms and conditions of the Creative Commons Attribution license (http://creativecommons.org/licenses/by/4.0/). 